\title{
A Genetic Study of Stub Thumbs among Various Ethnic Groups in Israel
}

\author{
RICHARD M. GOODMAN*, AVINOAM ADAM, and CHAIM SHEBA \\ From the Institute for Human Genetics, Tel Hashomer Government Hospital, Israel
}

Stub thumbs or brachymegalodactylism, a term coined by Hefner (1924), refers to the condition of having an abnormally or disproportionately short thumb on one or both hands. This anomaly has been recognized for many years and among palm readers and fortune tellers it has been called 'murderer's thumbs'.

Breitenbecher (1923) first reported a pedigree of five generations with this condition involving both thumbs and showed that the trait was inherited as an autosomal dominant. Since then there have been other reports describing this anomaly on one or both thumbs and in some cases other skeletal anomalies of the hands and feet have been noted in conjunction with the stub thumbs (Hefner, 1924; Sayles and Jailer, 1934; Wildervanck, 1955; Stecher, 1957). This genetically determined trait has been observed in many populations and there has been information to suggest differences in its occurrence among populations and between the sexes (Stecher, 1957).

The purposes of this investigation were to determine the frequency of this trait among the various ethnic groups in Israel, to note whether a specific skeletal anomaly may be associated with it, and to determine whether this trait could be distinguished further by analysis of thumb-prints.

\section{Subjects and Methods}

Tel Hashomer Hospital is one of the largest hospitals ( 880 beds) in Israel and admits a Jewish population that is approximately half Ashkenazim and half non-Ashkenazim. (Ashkenazim are Jews who come from Central and Eastern Europe, while the non-Ashkenazim include Jews from the Mediterranean basin (Sephardim) and those from the Middle Eastern countries of Iraq, India, and Yemen.) Approximately $6 \%$ of the patients admitted to the hospital are Arabs.

Initially, our study began by randomly surveying the hospital personnel and patients. Later the survey was extended to observe the frequency of this trait among a group of student nurses and army recruits (males and

\footnotetext{
Received October 22, 1964.
}

* Present address: Department of Medicine, Ohio State University, College of Medicine, Columbus, Ohio, U.S.A. females) Our total sample of Jews consisted of $1,850 \overrightarrow{\vec{\omega}}$ unrelated subjects (I,449 males and 401 females). Theo Arab sample was taken mainly from a school in a singles village where 490 boys and 383 girls were examined the addition of a few hospital patients made a total of 887 Arabs.

Apart from probands ascertained through this survey, $\overrightarrow{\vec{\sigma}}$ we were introduced to a number of affected people whose families were investigated subsequently. A question naire was completed on each affected individual and this included a family history and comments on observations of the hands and feet. In many cases, familyd visits were made to gain further data and to check theaccuracy of previous information. Reliable information on probands' relatives was obtained for 61 families. In ${ }^{\top 7}$ 19, this information included parents, sibs, and offspring, while the rest comprised families in which information was available regarding only one or two of these categories of relatives. When possible, thumb- ָे prints were taken of both thumbs, and in selected cases $\frac{\mathrm{D}}{\mathbb{D}}$ photographs and radiographs were made of the handso and feet.

Controls for thumb-print analysis in females were 3 obtained by taking finger prints of the thumbs only of student nurses and by analysing the thumb-prints of ac sample of women taken by the Israeli Police. Data for comparison of male thumb-prints were based on previous observations made by Sachs and Bat-Miriam: in 1957 .

\section{Results}

Clinical Observations. The clinical appear -2 ance of a stub or short thumb can be recognized? easily at a glance. The distal end of the thumb is $D$ short and tends to be thick, while the nail is alsoㅡ. broad and short. Fig. I shows the typical appear- $\bar{N}$ ance when either one or both thumbs are affected. According to many affected individuals, the de- -0 formity was noted at birth by their parents. ThosecJ affected also stated they were able to recognize the anomaly in their children during infancy.

Radiographic studies show that the deformity of this trait is confined to the distal phalanx of the thumb. Breitenbecher (1923) compared radio-T logically the distal phalanx of the affected thumb with that of the normal thumb and found the distalo phalanx in the affected to be one-half the length of 

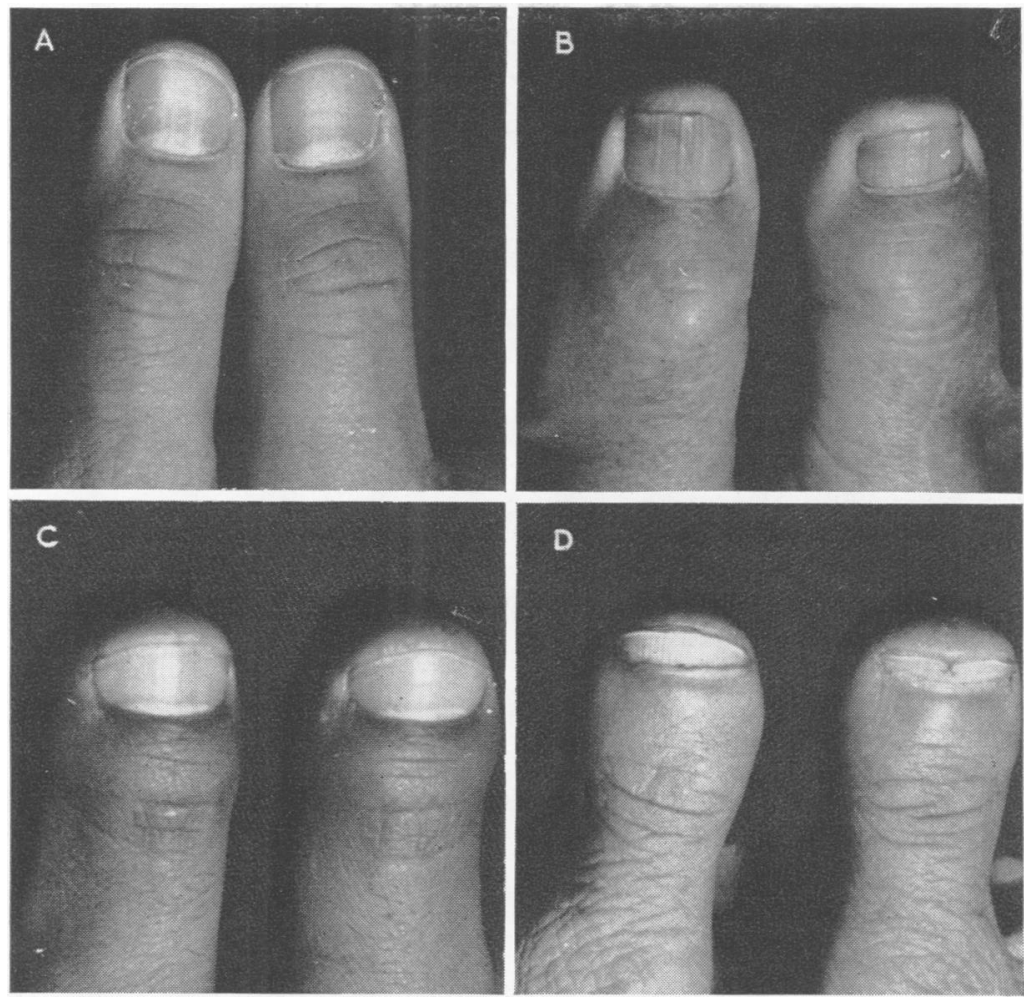

FIG. I. (A) normal thumbs, (B) only right thumb affected, (C) bilaterally affected thumbs, and (D) very affected stub thumbs; note the extremely short wide nails and flaring of the distal ends of the abnormal thumbs.

the normal. Stecher (1957) stated that the distal phalanx of the affected thumb was about twothirds the usual length. This discrepancy is understandable as our observations have shown that

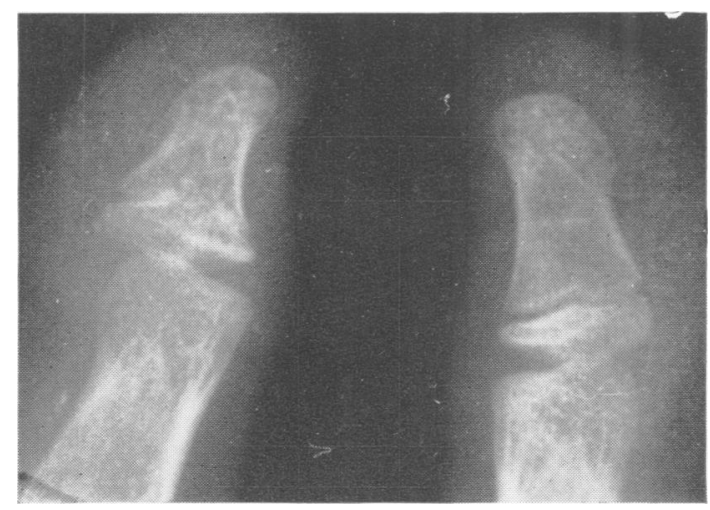

Fig. 2. Radiograph of a stub and normal thumb in a 12-year-old girl. The stub thumb is due to a short distal digit caused by a partially closed epiphysis. there can be considerable variation in the expression of this trait. Fig. 2 and 3 show that this abnormality results from a partial fusion or premature closing of the epiphysis with the distal phalanx of the thumb.

Frequency. Table I summarizes the total number of unrelated individuals observed and affected in each ethnic group. Of the $1,850 \mathrm{Jews}$, $29(1.57 \%)$ had one or two affected thumbs. The distribution of these people according to community, sex, and affected thumb is shown in Table $I$. Statistical analyses reveal no significant difference in these respects, and the whole sample may be regarded as a homogeneous population $\left(\chi^{2}=29.94\right.$; $\left.\mathrm{p}_{(27)}>0.3\right)$.

Among 887 Arabs, $27(3.05 \%)$ had stub thumbs. The incidence of affected people in the Arab sample was significantly higher than that in the Jews $\left(\chi^{2}=6.52 ; \mathrm{p}_{(1)}<0.02\right)$. This statement, however, should be considered with some reservation, since the 6,000 inhabitants of the village in which the school was located belonged to only is 


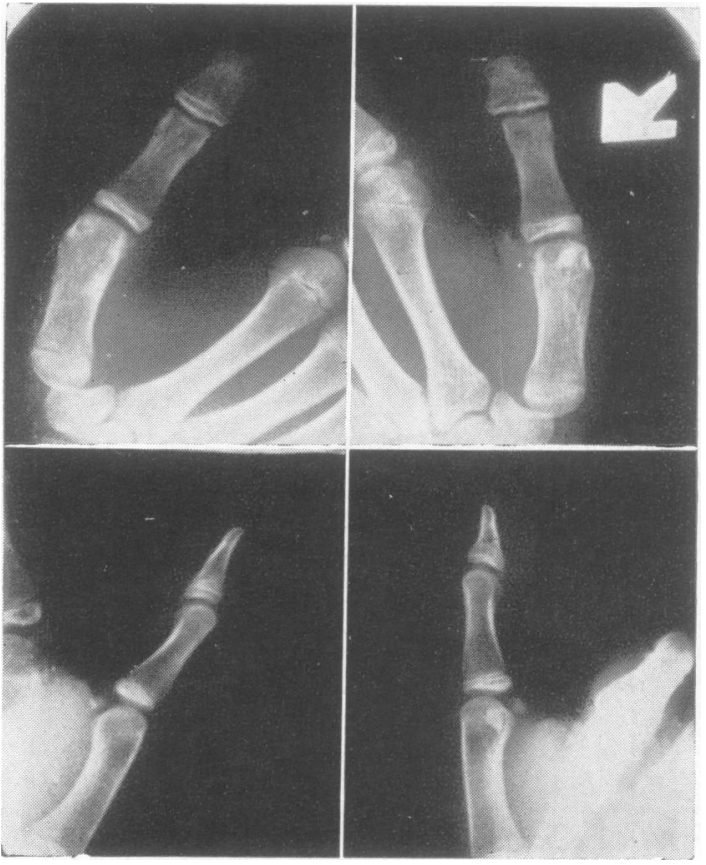

Fig. 3. Radiograph of a normal and stub thumb in a 14-year-old boy. Only the distal phalanx of the affected thumb is short and the epiphysis is closed.

large kinships. These kinships were said to be represented in the schools with approximate proportionality to their numbers, but the incidence of stub thumbs did not correspond with size of the family groups. For example, four of the affected children were members of the fifth largest family group, while no affected individuals were observed who belonged to a larger kinship. Family relationships were most complicated and could not be evaluated satisfactorily.

Inheritance. Our family material, which consists of over 60 pedigrees, agrees with previous observations that this trait, whether bilateral or unilateral, is inherited as an autosomal dominant (Table II and Fig. 4). As may be seen in Table II, information was available on parents of 49 probands. Only 25 of their 98 parents were affected, which would mean about $50 \%$ penetrance on the assumption of simple dominance. Penetrance among sibs and offspring seems to be still lower. The whole material yields a proportion of 53 affected to 197 non-affected relatives (about $42 \%$ of the expected ratio of $I: I)$. There was no statistical difference between the numbers of affected relatives of unilaterally and bilaterally affected probands.

Though $\mathrm{X}$ linkage of this trait could be excluded since there were many instances of father to son transmission, there seemed to be some sex influence. Of the 25 affected parents 18 were of the same sex as the proband (expected number for simple autosomal dominance is $12.5 ; \chi^{2}=4.0$; $p<0.05)$ and the same trend remained when other affected members of these families were included -52 of 83 relatives were of the same sex as the probands.

There were several instances in which unilateral and bilateral stub thumbs occurred in the same family along with families with only unilateral or bilateral involvement. There were three families in which two members were affected on only one thumb and three families with three unilaterally affected individuals. All of these pairs and trios

TABLE I

STUB THUMBS IN ISRAELI COMMUNITIES (RANDOM SAMPLES)

\begin{tabular}{|c|c|c|c|c|c|c|c|c|}
\hline \multirow{2}{*}{ Community } & \multirow{2}{*}{ Sex } & \multirow{2}{*}{$\begin{array}{l}\text { Number } \\
\text { Examined }\end{array}$} & \multicolumn{5}{|c|}{ People with Affected Thumbs } & \multirow{2}{*}{$\pm \underset{\text { Error }}{\text { Standard }}$} \\
\hline & & & Right & Left & Both & Total & $\%$ & \\
\hline $\begin{array}{l}\text { fews } \\
\text { Ashkenazim (Central and Eastern Europe) } \\
\text { Sephardim (Southern Europe) } \\
\text { Sephardim (North Africa) } \\
\text { Oriental, Iraqi, and Iranian } \\
\text { Yemenite }\end{array}$ & $\begin{array}{l}\mathbf{M} \\
\mathbf{M} \\
\mathbf{F} \\
\mathbf{M} \\
\mathbf{F} \\
\mathbf{M} \\
\mathbf{F} \\
\mathbf{M} \\
\mathbf{F}\end{array}$ & $\begin{array}{r}584 \\
261 \\
182 \\
30 \\
254 \\
48 \\
250 \\
28 \\
179 \\
34 \\
\end{array}$ & $\begin{array}{l}\underline{z} \\
\bar{Z} \\
\underline{I}\end{array}$ & $\begin{array}{l}\frac{1}{2} \\
\frac{-}{2} \\
\frac{1}{1}\end{array}$ & $\begin{array}{r}2 \\
3 \\
1 \\
1 \\
2 \\
1 \\
2 \\
-1 \\
-\end{array}$ & $\begin{array}{l}8 \\
6 \\
3 \\
1 \\
2 \\
1 \\
4 \\
1 \\
3 \\
\end{array}$ & $\begin{array}{l}I \cdot 66 \\
I \cdot 89 \\
0 \cdot 99 \\
I \cdot 80 \\
I \cdot 4 I\end{array}$ & $\begin{array}{l} \pm 0.44 \\
\pm 0.94 \\
\pm 0.57 \\
\pm 0.80 \\
\pm 0.81\end{array}$ \\
\hline Total Jews & $M$ and $F$ & 1850 & 7 & 9 & 13 & 29 & $\mathbf{I} \cdot 57$ & \pm 0.29 \\
\hline Arabs & $\begin{array}{l}\mathbf{M} \\
\mathbf{F}\end{array}$ & $\begin{array}{l}496 \\
391 \\
\end{array}$ & $\begin{array}{l}I \\
4\end{array}$ & $\begin{array}{l}5 \\
2\end{array}$ & $\begin{array}{l}6 \\
9\end{array}$ & $\begin{array}{l}12 \\
15\end{array}$ & & \\
\hline Total Arabs & $M$ and $F$ & 887 & 5 & 7 & 15 & 27 & $3 \cdot 05$ & \pm 0.58 \\
\hline
\end{tabular}




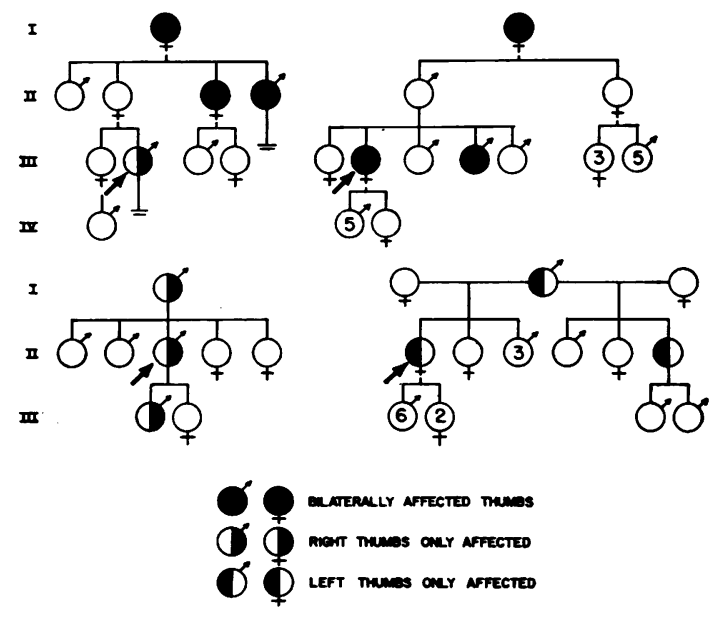

Fig. 4. Pedigrees of families with stub thumbs. The figures inside the symbols indicate the number of subjects.

were concordant as to which thumb was affected (Fig. 4). Another concordant pair and a trio were recorded by Hefner (1924) and one more pair by Sayles and Jailer (1934). It is highly improbable that this concordance is due to chance alone; the probability for a pair to be concordant is 0.5 and for a trio 0.25 and pooling all 9 cases, $p=(0.5)^{5} \times$ $(0.25)^{4} \cong 0.0001$, but even our personal observations of the 6 concordant families are significant $(p \cong 0.002)$ and suggest a genetic factor in determination of this phenotype. Personal observation or reliable information on probands' parents was available in 49 cases (21 males, 28 females). Only 25 of them ( 13 males, I2 females) had an affected parent, and penetrance among sibs and offspring seemed to be still lower. It should be mentioned that our information on relatives other than parents was incomplete in several cases. In general, penetrance appeared to be approximately $40 \%$ and no difference could be detected in those families affected predominantly bilaterally or unilaterally.
Thumb-prints. For our male control frequencies of thumb-print patterns, we used the observations of Sachs and Bat-Miriam (1957), who examined the fingerprints of 4,000 unrelated Jewish males from various ethnic groups (500 males from 8 communities) and concluded that these communities did not differ in the distribution of patterns on all Io digits. We arrived at the same conclusion with regard to females when analysing the thumbprints of I80 unrelated normal Jewish females. They belonged to the same communities as our sample of affected ones and were distributed with approximately the same frequencies. We have found this sample to be uniform and to conform to the 'rule of pairs', according to which there is a significant tendency towards symmetry, namely, that the two thumbs present a similar pattern more frequently than would be expected for a random distribution. The frequencies of the patterns were very similar to those reported in the males, the prevalence of whorls being slightly lower in females (similar differences between sexes are cited by Cummins and Midlo (1943) for other populations). Table III shows that affected thumbs have more whorls than normal ones in both sexes and on both hands.

Since about half of these people were affected on both thumbs and since the rule of pairs prevails, we could not pool data of right and left thumbs. However, on pooling data of males and females for each hand separately, it was observed that stub thumbs had a statistically significant higher frequency of whorls than normal thumbs (Table III).

Other Anomalies. The most frequent anomaly associated with the stub thumbs was a short fourth toe. Fig. 5 shows that this feature is due to a short fourth metatarsal with a short proximal phalanx. This was observed in four unrelated individuals among whom there were three cases of bilateral occurrence. In one family, two other members known to have stub thumbs were also reported

TABLE II

DISTRIBUTION OF STUB THUMBS IN FAMILIES OF 6I PROBANDS

\begin{tabular}{|c|c|c|c|c|c|c|c|c|c|c|c|c|c|}
\hline \multirow{2}{*}{ Proband } & \multirow{2}{*}{ Number } & \multicolumn{4}{|c|}{ Parents } & \multicolumn{4}{|c|}{ Sibs } & \multicolumn{4}{|c|}{ Offspring } \\
\hline & & Affected & $\begin{array}{c}\text { Not } \\
\text { Affected }\end{array}$ & Unknown & Total & Affected & $\begin{array}{c}\text { Not } \\
\text { Affected }\end{array}$ & Unknown & Total & Affected & $\underset{\text { Affected }}{\text { Not }}$ & Unknown & Total \\
\hline $\begin{array}{l}\text { Both thumbs } \\
\text { affected } \\
\text { One thumb } \\
\text { affected }\end{array}$ & $\begin{array}{l}32 \\
29\end{array}$ & $\begin{array}{r}14 \\
\text { I I }\end{array}$ & $\begin{array}{l}40 \\
33\end{array}$ & $\begin{array}{l}10 \\
14\end{array}$ & $\begin{array}{l}64 \\
58\end{array}$ & $\begin{array}{r}\text { is } \\
9\end{array}$ & $\begin{array}{l}62 \\
33\end{array}$ & $\begin{array}{r}29 \\
17\end{array}$ & $\begin{array}{r}106 \\
59\end{array}$ & $\begin{array}{l}3 \\
\mathbf{I}\end{array}$ & $\begin{array}{l}18 \\
\text { II }\end{array}$ & $\begin{array}{l}4 \\
4\end{array}$ & $\begin{array}{l}25 \\
16\end{array}$ \\
\hline Totals & 61 & 25 & 73 & 24 & 122 & 24 & 95 & 46 & 165 & 4 & 29 & 8 & 41 \\
\hline
\end{tabular}


TABLE III

ANALYSIS OF THUMB-PRINT PATTERNS ON STUB THUMBS

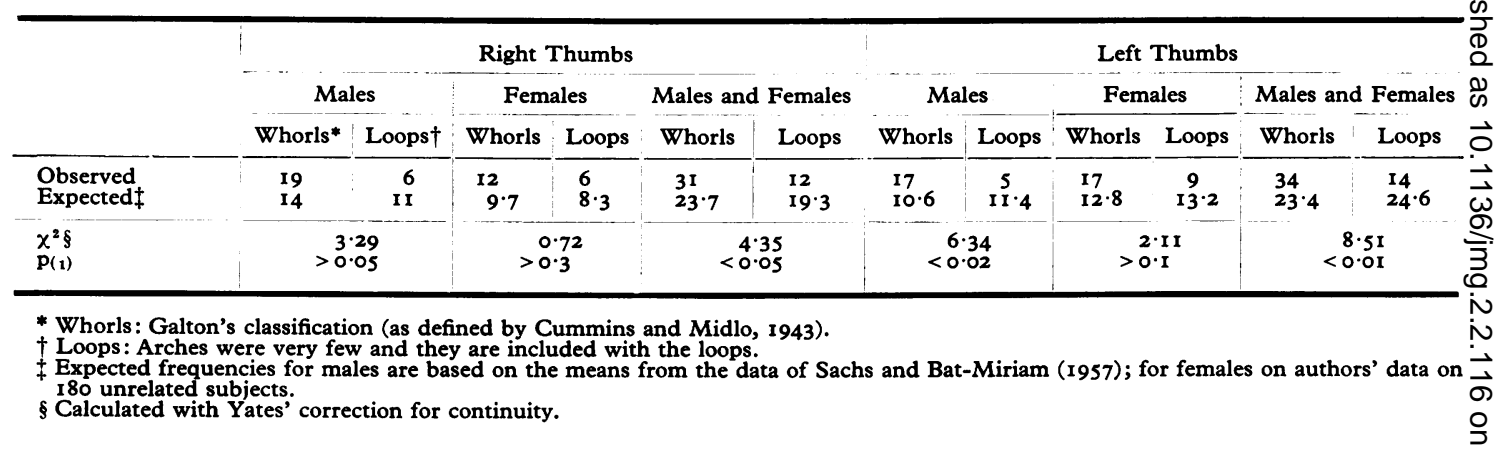

to have this anomaly. In another family, a father and son with bilaterally affected thumbs had identically affected short toes on the right, while another member had no thumb involvement but brachydactyly of the fourth and fifth digits of both hands and bilateral short fourth toes.

Syndactyly of the second and third toes was noted in two cases, while another showed webbing of all fingers of both hands and a fusion of the

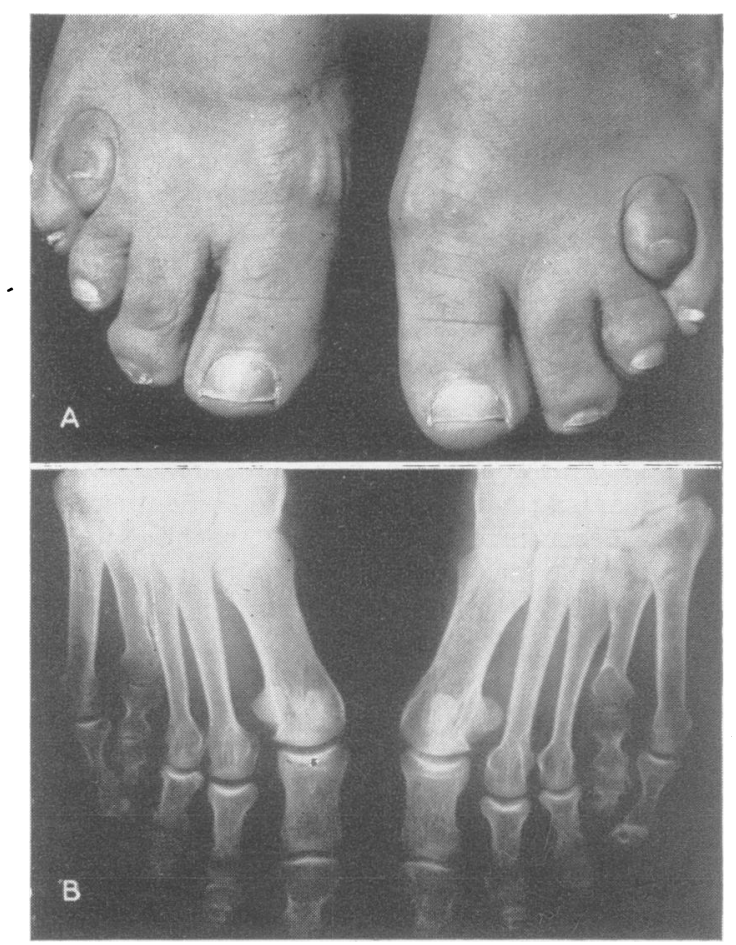

Fig. 5. (A) Illustrates the short fourth toe associated with the stub thumb. (B) Illustrates a short fourth metatarsal with a short proximal phalanx. middle phalangeal joints of the fourth and fifth $\vec{c}$ digits of both hands. Yet another had a congenital $\subsetneq$ malformation of the heart with dextrocardia, and $\bar{D}$ in one of the previously mentioned families several $\vec{\varphi}$ members are currently being studied for familial of aggregation of a disturbance in cardiac conduction.

\section{Discussion}

Studies of Jewish populations have revealed striking differences among the various communities $\frac{\mathscr{O}}{D}$ in the frequencies of many genes, but no less striking $\cong$ has been the homogeneity found in the frequencies $\vec{B}$ of other genetically determined disorders (Gold- 3 schmidt, 1963). Some of the latter are manifested by so-called selectively neutral traits. Their? homogeneous distribution in Jewish groups isolated from each other for many generations and the fact that their frequencies were in some cases different $\frac{0}{3}$ from those found in non-Jews of the same countries of origin, have been interpreted as evidence for a $O$ common ancient Eastern Mediterranean gene pool of the present-day Jewish communities (Sachs and Bat-Miriam, 1957).

The same reasoning might be extended to suggest that the stub thumb is another example of $N$ this feature, since it seems to be selectively neutral and its distribution among the various communities 0 is quite homogeneous. However, data on its fre- $\mathrm{\omega}$ quencies among non-Jews are meagre. The mean frequency of $1 \cdot 57 \%$ observed in this study among Jews is similar to the $1.5 \%$ estimate of Pfitzer as $\Phi$ quoted by Köhler (I93I). It has not been men- $\stackrel{\infty}{+}$ tioned what population was surveyed by Pfitzer, $T$ nor whether one or both affected hands were included in his estimate, but it is interesting that these two estimates are much higher than the $\stackrel{\mathbb{Q}}{\mathbb{Q}}$ frequencies of $0.4 \mathrm{r} \%$ and $0.1 \%$ found by Stecher (1957) in U.S. white and Negro populations respectively. The still higher frequency found among Israeli Arabs may be explained by the special 
characteristics of our sample as mentioned previously. It would be of interest to know whether this high frequency could be confirmed by studying other Arab samples.

It has long been observed that many of the genetic anomalies of the skeleton are inherited as autosomal dominants and it is not surprising to find that stub thumbs also adhere to this mode of inheritance. Only Stecher (1957), who collected extensive data, concluded that stub thumbs were inherited as a single recessive with irregular penetrance. His analyses of the ratios of affected to normals among the probands' sibs were not consisient with either simple recessive or dominant inheritance. But since the fit on the assumption of dominance was poorer, he adopted the recessive hypothesis. However, if allowance is made for reduced penetrance among sibs (as was done by Stecher for parents only) the dominant hypothesis is readily acceptable.

The reduced penetrance and the variability in the expression of the trait are evidenced by its occasional unilateral appearance. Unilaterality and concordance as to affected side have been observed in another bilateral condition such as coxa plana (Dunn, 1960). Together with our observation on stub thumbs, these findings support previous suggestions as to the operation of modifying genes in these conditions. Some of the possible interpretations have been discussed by Walker (I96I). These modifiers could not be evaluated in the present study since our family material was insufficient.

Further characterization of this anomaly has been attempted by the use of thumb-printing. The increase in the frequency of whorls on the affected thumbs (Table II) has not been noted previously. Since the genetic mechanism of fingerprint patterns is still obscure, it is difficult to assess the significance of this association.

The additional observation of a short fourth toe suggests that this finding too may be significant, rather than just a random association. The same anomaly was seen by Stecher (1957) once in 95 short-thumbed individuals. This observation needs further investigation since other skeletal anomalies have also been reported (Köhler, 193I; Wildervanck, 1955; Stecher, 1957) in conjunction with stub thumbs. None of the other reported anomalies have occurred as frequently as our observation regarding a small fourth toe.

Much of the data presented in this report, such as the genetic component determining consistency in unilateral expression of the trait, the possible sex influence, and the partial association with a dermatoglyphic pattern, and another skeletal anomaly suggest that polygenes may be involved in the expressivity of the gene producing a stub thumb.

It is unfortunate that this simple trait is not suitable for use as a genetic marker in linkage studies because of its low penetrance. Additional studies of this trait are warranted to determine its frequency in other populations and to evaluate previously mentioned features in association with the stub thumb.

\section{Summary}

A genetic study of stub thumbs was carried out among various ethnic groups in Israel. No significant difference in the prevalence of the trait was observed among the various Jewish communities.

Approximately $1.6 \%$ of Jews and $3 \%$ of Arabs were affected, half of them bilaterally. The two sexes were affected equally. Autosomal dominant inheritance was confirmed and penetrance was approximately $40 \%$.

Unilaterally and bilaterally affected individuals were observed in the same family, but when two or more members of a family were affected unilaterally, it always occurred on the same hand.

A significant increase in the frequency of whorls was noted on affected thumbs. Among anomalies that appeared in association with stub thumbs, the most common was a short fourth toe.

We are obliged to the following who gave us much help with our study: Colonel E. Gilon, Surgeon General of the Israeli Defence Forces; $\mathrm{Mr} \mathrm{Z}$. Leiber of the Israeli Police Headquarters; Mrs S. Zimet, Director of Student Nursing at Tel Hashomer Hospital; Dr S. Schocat, Director of the Health Center, Tira; Mr D. Adam of Kibbutz Hulata; Mr I. Ahrak of Rosh Ha'ain; and the medical staff of Tel Hashomer Hospital.

\section{REFERENCES}

Breitenbecher, J. K. (I923). Hereditary shortness of thumbs. f. Hered., $14,15$.

Cummins, H., and Midlo, C. (1943). Finger Prints, Palms and Soles: An Introduction to Dermatoglyphics. Blakiston, Philadelphia.

Dunn, A. W. (1960). Coxa plana in monozygotic male twins. F. Bone It Surg., 42 A, 178.

Goldschmidt, E., Editor (1963). The Genetics of Migrant and Isolate Populations. Williams and Wilkins, New York.

Hefner, R. A. (1924). Inherited abnormalities of the fingers. II Short thumbs (brachymegalodactylism). F. Hered., 15, 433.

Köhler, A. (I93I). Roentgenology. William Wood, New York.

Sachs, L., and Bat-Miriam, M. (1957). The genetics of Jewish populations. I. Finger print patterns in Jewish populations in Israel. Amer. F. hum. Genet., 9, 117.

Sayles, L. P., and Jailer, J. W. (1934). Four generations of short thumbs. $\mathcal{F}$. Hered., 25, 377.

Stecher, R. M. (1957). The physical characteristics and heredity of short thumbs. Acta genet. (Basel), 7, 217.

Walker, J. T. (I96I). A pedigree of extra-digit-V polydactyly in a Batutsi family. Ann. hum. Genet., $25,65$.

Wildervanck, L. S. (1955). Erfelijke brachyphalangie van der einkooties der duimen in twee families; in een dier families tevens hereditaire valgusstand van de Kleine tenen. Ned. T. Geneesk., $99,2137$. 